\title{
RANCANGAN SISTEM LUX METER DENGAN 5 SENSOR LDR DAN ARDUINO PADA SOFTWARE PROTEUS V8.0 SPO
}

\author{
${ }^{1)}$ Muhammad Navil , ${ }^{1)}$ Alex Harijanto , ${ }^{1)}$ Maryani \\ ${ }^{1)}$ Program Studi Pendidikan Fisika, FKIP, Universitas Jember \\ naviledogawa@gmail.com
}

\begin{abstract}
Abstrack
The simulation is generally used to present and as an initial stage for implementing a simple or complex system. The simulation is intended to find out whether the circuit is going whit what the designer wants. The purpose of this research was to design a light intensity meter using five LDR (Light Dependent Resistor) sensors and an arduino uno with an Atmega 328p IC. The simulation software used PROTEUS 28.0 SPO, Proteus is used because of its advantages: Interactive, easy to use, and with complete electronic components such as having active components (MOSFET Transistor, IC, diode, IGBT, BJT, etc.) and passive components such as capsitor, resistors, sensors from varius vendo,input and output pins, and is equipped with two modes, namely ISIS which contains SPICE and ARES mode, namely PCB loader. The designed system circuit consists of 3 main components, such as: 1) the LDR sensor as an input component; 2) the design of tools for processing input data; 3) I2C LCD $16 \times 2$ as the output display of the input data processing by the Arduino Uno microcontroller.
\end{abstract}

Keywords : Light Intensity; LDR; ArduinoUno; Software Proteus.

\section{PENDAHULUAN}

Manusia tidak bisa lepas dari pemanfaatan dan ketergantungan pada cahaya dalam kehidupan sehari-hari. Miasal dalam pemanfaatan lampu sebagai sumber cahaya buatan untuk membantu aktifitas manusia. Penerangan sangat bergantung pada jarak sumber cahaya, Cahaya merupakan gelombang elektromagnetik yang dapat di tangkap atau dilihat oleh mata manusia, sumber cahaya mengeluarkan energi yang beberapa diantaranya di ubah menjadi visible light atau cahaya tampak yang memiliki cepat rambat gelombang (v) diruang bebas adalah $3 \times 10^{8} \mathrm{~m} / \mathrm{s}$ dengan memiliki frekuensi sebesar $\mathrm{f}$ dan panjang gelombang sebesar $\lambda$ maka dapat di rumuskan dengan:

$$
\lambda=\frac{v}{f}
$$

Intensitas cahaya merupakan variabel fisika dimana sering dicari nilai besarannya dalam praktikum fisika optik. Salah satu jenis pengukuran intensitas cahaya adalah dengan mengukur intensitas cahaya dari berbagai sudut. Alat ukur intensitas cahaya yang tersedia di toko online maupun offline biasanya memiliki harga yang mahal. Dengan adanya sensor cahaya LDR dan mikrokontroller berupa board arduino sehingga alat ukur intensitas cahaya yang memiliki harga yang murah dapat di rancang.

Cara paling mudah dalam mengukur tingkat intensitas cahaya adalah dengan menggunakan papan arduino dan sensor LDR, dengan mengkombinasikan antara arduino dengan sensor-sensor lainnya arduino dapat dikembangkan untuk menjadi bagian dari pembelajaran lainnya (Thakur, 2016). Sensor LDR sangatlah mudah didapat 


\section{Jurnal Pembelajaran Fisika, Vol 9 No. 4, Desember 2020, hal 160-164}

dan dirangkai dengan karakteristik resisitansi yang bergantung pada nilai intensitas cahaya yang diterima.

Mikrokontroller atau pengendali mikro dalam rangkaian elektronika berfungsi sebagai pengontrol sekaligus pengolah data yang mengatur proses kerja dari suatu rangkaian elektronika. IC yang digunakan biasanya terdiri dari timer, CPU, serial komunikasi pararel, memori, port input dan output, ADC dll (Andrianto dan Darmawan, 2017). Chip mikrokontroller pada saat ini terdapat dalam Board arduino yang merupkan KIT elektronik dimana didalamnya memiliki variasi IC mikrokontroller bergantung type dari board arduinonya sehingga memudahkan seseorang dalam perakitan rangkaian elektronika meski tanpa mengetahui apa itu pemrograman (Schmit, 2013)..

Untuk merancang alat ukur intensitas cahaya menggunakan sensor LDR dan board arduino maka perlu dilakukan perancangan sistem lux meter dengan 5 sensor LDR dan arduino menggunakan software Proteus v8.0 SPO. Proteus merupakan salah satu software elektronika dari suatu perusahan Inggris yaitu labcenter elektronics yang digunakan desainer untuk merancang prototype dan mensimulasikan rangkaian elektronik. Proteus di dukung oleh banyak library sehingga membuat proteus menjadi software simulasi yang sangat lengkap mulai dari komponen pasif, IC, mikrokontroller alat ukur, transistor, dan komponen elektronika lainnya (Permana, 2016). Dengan alasan ini peneliti membuat perancangan sistem lux meter menggunakan 5 sensor LDR dan Arduino menggunakan software Proteus.

\section{METODE PENELITIAN}

Rancang bangun alat ukur intensitas cahaya dengan sensor LDR menggunakan software Proteus v8.0 SPO menggunakan beberapa komponen dalam bentuk virtual yaitu sebagai berikut: 1) lampu merupakan sumber cahaya yang yang akan di ukur intensitas cahayanya; 2) sensor light dependent resistor merupakan resistor yang memiliki nilai resistansi berubah-ubah bergantung dengan intensitas cahaya yang di terima LDR; 3) arduino uno merupakan board mikrokontroller dengan IC Atmega $328 \mathrm{p}$ yang berfungsi sebagai pengolah data yang di ukur sensor LDR.; 4) I2C /IIC (Inter Intergreted Cirkuit) atau TWI (Two Wire Interface) merupakan module LCD yang di kendalikan secara sinkronasi serial protokol; 5) LCD $16 \times 2$ merupakan modul yang berfungsi sebagai penampil data ukur sensor LDR yang telah di olah board arduino uno.

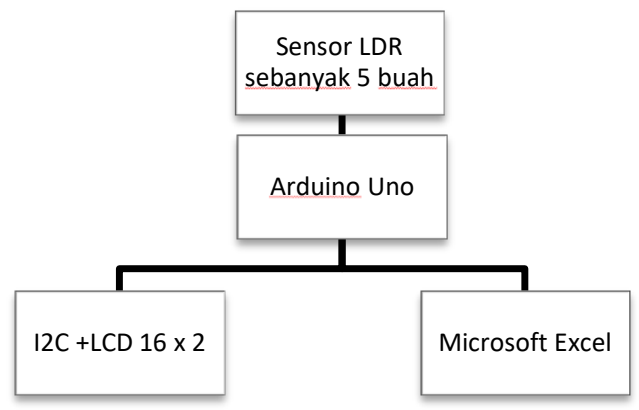

Gambar. 1 diagram blok alat rancangan

Cara kerja sistem yang di buat berdasarkan pada gambar. 2 karena menggunakan simulasi proteus v8.0 SPO di jelaskan dengan flowchart 


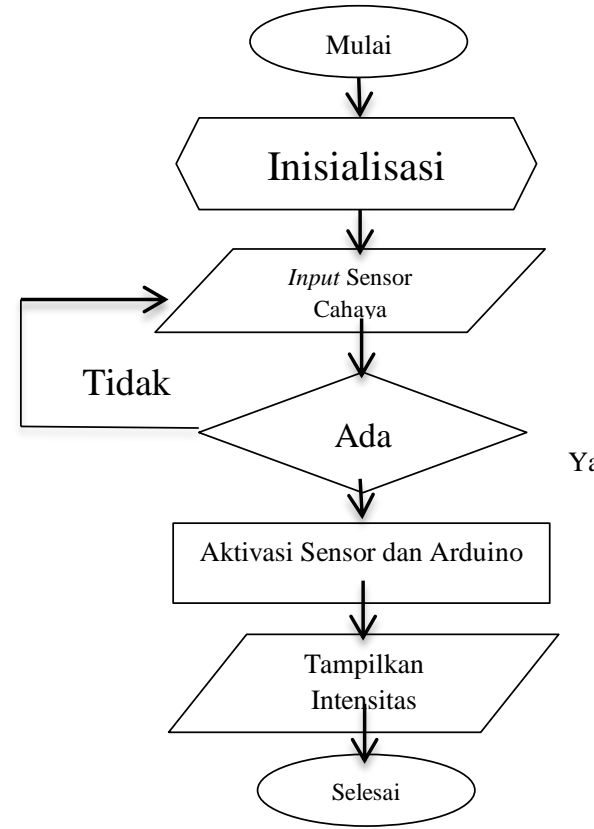

Gambar 2. Flowchart rancang sistem alat

Cara kerja rancang bangun sistem lux meter dengan sensor LDR menginisialisasi setelah inisialisasi selesai di lanjutkan dengan penerimaan input berupa cahaya oleh sensor LDR (Light Dependent Resistor) jika tidak ada cahaya maka proses akan kembali pada input data oleh sensor LDR dan jika ada cahaya proses duilanjutkan dengan aktivasi sensor LDR dan Arduino, setelah aktivasi sensor dan Arduino maka data input dari sensor LDR akan di olah oleh Arduino dan di tampilkan pada LCD 16x2

\section{HASIL DAN PEMBAHASAN}

Tahap awal dilakukan perancangan sistem I2C dan LCD 16x2, kaki I2C di hubungkan pada LCD 16 x 2 dengan urutannya adalah menghubungkan D7 LCD pada P7 I2C, D6 LCD pada p6, D5 LCD pada P5 I2C, D4 LCD pada P4 I2C, kaki E LCD dihubungkan dengan P2 I2C, kaki RW LCD dihubungkan pada P1 I2C, dan kaki RS LCD dihubungkan dengan kaki p0 LCD. Dilanjutkan dengan menghubungkan I2C pada mikrokontroller arduino uno, dengan rangkaian $\mathrm{A} 0, \mathrm{~A} 1$, dan $\mathrm{A} 2$ dihubungkan dengan pin daya $5 \mathrm{~V}$, pin SCL I2C dihubungkan dengan pin A4 atau SCL Arduino, dan kaki SDA I2C di hubungkan pada pin A5 atau pin SDA Arduino. tahap ini dilakukan untuk menguji apakah rangkaian LCD terpasang dengan benar dan mengetahui apakah program I2C LCD dapat bekerja dengan apa yangdi inginkan peneliti rangkaian pengujian LCD dibuat dengan software Proteus V8.0 seperti rangkaian berikut:

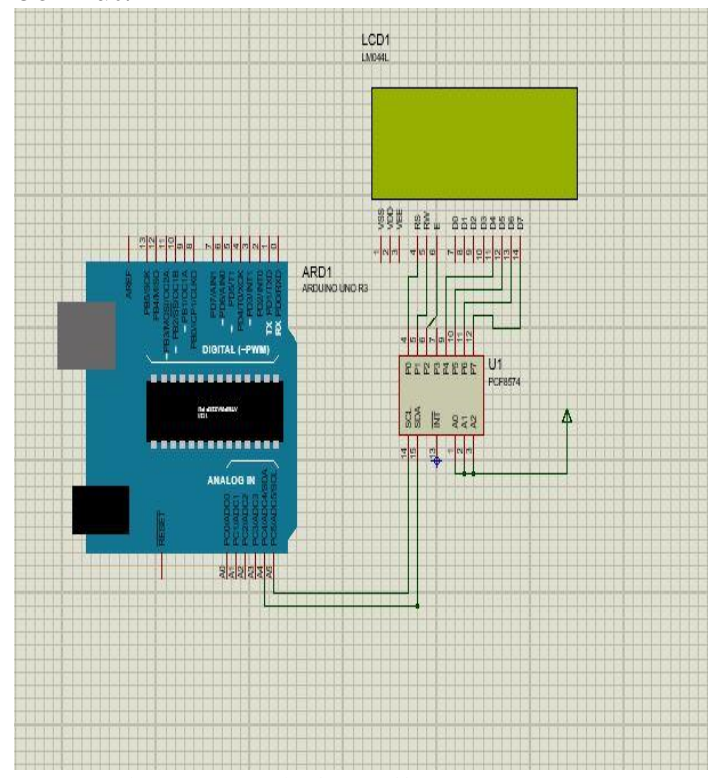

Gambar 3 rangkaian uji I2C LCD 16 x 2

Tahap berikutnya dilakukan perangkaian sensor LDR sebanyak lima buah pada rangkaian Arduino uno dan I2C LCD 16x2 dengan menhubungkan sensor 1 dihubungkan pada pin analog 0 (A0) sensor LDR 2 dihubungkan pada pin analog 2 (A1), sensor LDR 3 dihubungkan pada pin analog 3 (A2), sensor LDR 4 dihubungkan pada pin analog 3 (A3), dan sensor LDR 5 dihubungkan pada pin Analog 4 (A4), dengan masing-masing sensor dihubungkan seri dengan reisitor dengan besar $10 \mathrm{k}$ ohm dan disusun secara pararel terhubung dengan pin power dengan daya 5 Volt dan ground (gnd) setelah dirangkai menggunakan software Proteus didapatkan sebagai berikut: 


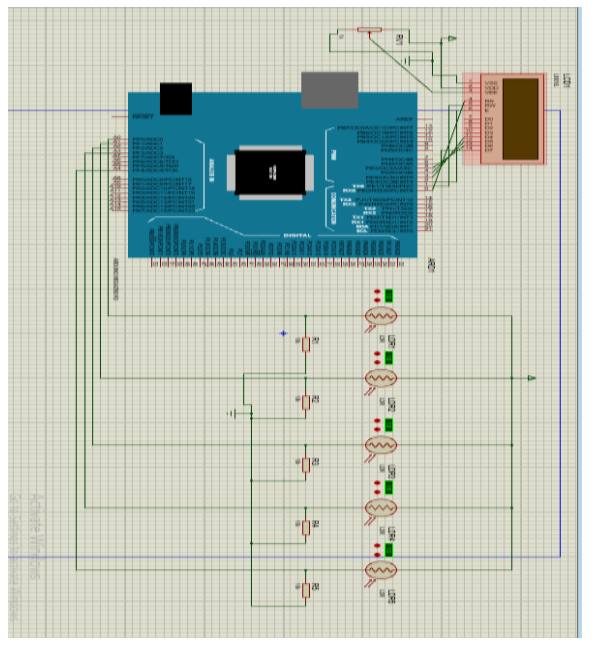

Gambar 4. Rangkaian sensor LDR dan LCD

Kemudian dilanjutkan dengan pembuatan program menggunakan software IDE Arduino, program pertama adalah penguploadan library LCD 16x 2, I2C dan komunikasi wire, kemudian dilanjutkan dengan menginisialisasi masing-masing pin pada Arduino, kemudian di lanjutkan dengan program persamaan untuk mengkonvert dari resistansi ke besaran lux yaitu menggunakan perintah sensor Value $=$ analogRead $($ pin analog LDR); dan perintah float lux= $((500.0 / 1024) *$ sensorValue $) * 0.1 ; . \quad$ lalu dilanjutkan dengan upload pada rangkaian simulasi Proteus v8.0 SPO.

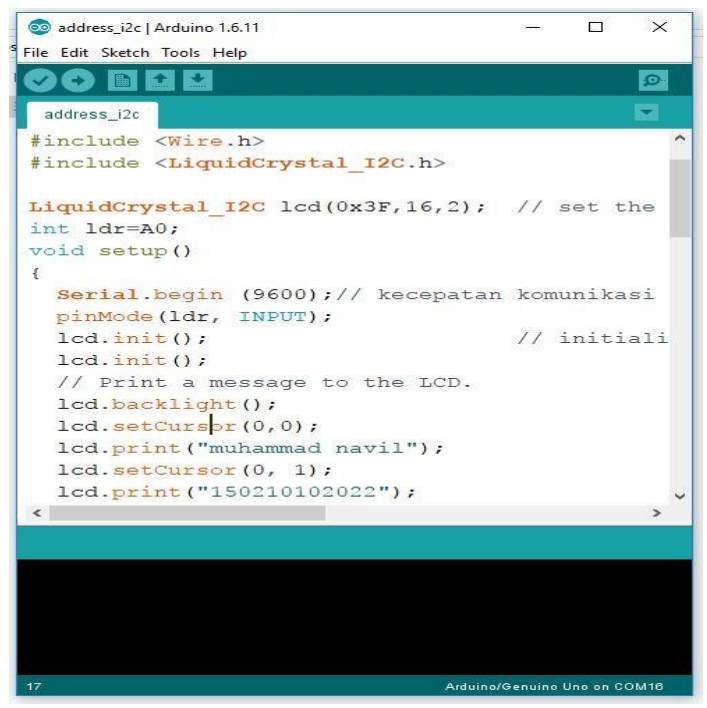

Gambar 5. Program IDE arduino

Sensor Light Dependent Resisrtor (LDR) adalah sebuah resistor dua kaki yang memiliki kepekaan terhadap cahaya, saat menenerima cahaya yang semakin kecil maka nilai resitansinya akan semakin besar hal ini dapat di lihat pada gambar

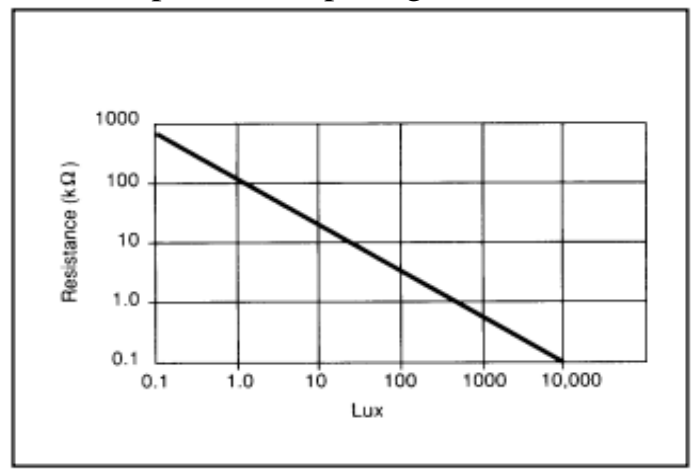

Gambar. 4 hubungan resistansi dan lux

Untuk perancangan secara hardware data akan dinyatakan valid apabila sesuai denga Persamaan untuk interverensi yang di tulis dengan:

$$
\begin{gathered}
\phi=-\frac{2 \pi}{\lambda} \Delta L \\
E_{1}\left(r_{1}, t\right)=E_{0} \cos \left(k r_{1}-\omega t\right) \\
E_{2}\left(r_{2}, t\right)=E_{0} \cos \left(k r_{1}-\omega t+\phi\right) \\
E_{0}{ }^{\prime}=2 E_{0} \cos \left(\frac{\phi}{\lambda}\right) \cos \left(k r_{1}-\omega t+\phi\right)
\end{gathered}
$$

Dengan melihat hubungan Amplitudo dengan intensitas maka di dapatkan persamaan sebagai berikut:

$$
\begin{aligned}
& I=4 I_{0} \cos ^{2}\left(\frac{\phi}{\lambda}\right) \\
& \phi=\frac{2 \pi}{\lambda} d \sin \theta
\end{aligned}
$$

Dan nilai dari $\cos (-x)=\cos (x)$ maka persamaan di atas bisa di tulis dengan:

$$
I=4 I_{0} \cos ^{2}\left(\frac{\pi}{\lambda} d \sin \theta\right)
$$

Atau

$$
\mathrm{I}=\mathrm{Id} \cos ^{2}\left(\frac{\pi}{\lambda} d \sin \theta\right)
$$

Dengan besarnya intensitas cahaya bergantung dengan nilai dari $\cos ^{2}$ dan intensitas maksimal didapat jika 
$\cos ^{2}\left(\frac{\pi}{\lambda} d \sin \theta\right)=1$ atau $\left(\frac{\pi}{\lambda} d \sin \theta\right)=$ $\pm 0, \pm \pi, \pm 2 \pi, \ldots . \pm n \pi \quad$ (Guenter. 1990). Dari persamaan di atas bisa di ketahui bahwa intensitas maksimal bergantung pada nilai sudut $\cos$ square $=1$.

\section{SIMPULAN DAN SARAN}

Rancang sistem lux meter menggunakan 5 sensor LDR dan arduino dengan berbantukan software Proteus v8.0 SPO dan mendpat hasil sesuat yang di inginkan peneliti. Alat ini bekerja dengan cara mengukur resistansi dari sensor LDR yang berubah-ubah bergantung dengan cahaya yang di terima oleh sensor LDR, dengan memperhatikan datasheet sensor LDR, perubahan resistansi di convert kedalam besaran lux, pengkonvertan dilakukan melalui program menggunakan IDE Arduino yang di tanamkan pada IC Atmega328 yang ada pada arduino uno. Dengan menggunakan board arduino perancangan akan menjadi sangat mudah, lebih terkostumisasi, dan dalam pengimplementasian yang lebih praktis.

\section{SARAN}

Berdasarkan penelitian yang telah dilakukan, peneliti menyarankan untuk mensimulasikan dengan sensor-sensor dan rangkaian elektronika yang lain menggunakan software Proteus dengan versi v8.0 atau versi lainnya.

\section{DAFTAR PUSTAKA}

Feriyana, O. S., Kamus, Z. , 2019, Pembuatan Alat Ukur Sudut Datang dan Intensitas Cahaya Matahari Real Time Menggunakan Sensor Accelerator dan LDR, Padang, Jurnal Pillar of Physics, Vol 12, No. 1, Universitas Padang

Halliday, David \& Resnick, Robert. 1991. Fisika. Translated by Pantur Silaban dan Erwin Sucipto. Jakarta: Erlangga.
Harijanto, Alex, 2019, Buku Ajar Kuliah Sensor dan Transducer, Jember, Universitas Jember

Herawadi S. N., dan Ridho .M., 2015. Pendeteksi tanah longsor menggunakan sensor Cahaya. Jurnal TIM Darmajaya. 1(2): 219.

Hikam, Muhammad, et al. 2005. Eksperimen Fisika dasar Untuk Perguruan Tinggi. Jakarta: Prenada Media.

Kubinova, S., Slegr, J., 2015, Physics Demonstrations with Arduino Board, IOP Science, Physics Education, Vol. 50, No. 472

Pamungkas, M., Hafiddudin, dan Rohmah, Y. S., 2015, Perancangan dan Realisasi Alat Pengukur Intensitas Cahaya, Jurnal Elkomia, Teknik Elektro ITENAS, No. 2, Vol. 3

Saputra, f.a., purfaji., \& wicaksana, d. 2013. mekatronika tentang pembuatan robot sumo

Stallings, w. 2004. Data and computer communications 7 th edition. New jersey: pearson prentice hall.

Thakur, M. R., 2016, Measurement Made Simple with Arduino, Delhi, Kindle.

Tipler, Paul A. (1998). Fisika Untuk Sains dan Teknik Jilid 1. Erlangga: Jakarta. 